\title{
Ethical Decision Making in Issues Management
}

\author{
Prof Seyed Mehdi Alvani ${ }^{1}$, Shohrehosadat KarimiJahromi ${ }^{2}$ \\ ${ }^{1}$ (Faculty member of Public Administration, Qazvin Branch, Islamic Azad University, Qazvin, Iran) \\ ${ }_{2}^{2}$ (Ph .d. Student in Public Administration, Central Tehran Branch, Islamic Azad University, Tehran, Iran)
}

\begin{abstract}
Issues management (IM) is becoming widely accepted in the business-and-society literature as a policy tool to enhance the social performance of corporations. Its acceptance is based on the presumption that firms have incorporated ethical norms into their decision-making process. This paper argues that IM is simply a technique to identify, analyze, and respond to social issues. It can be used either to improve or forestall corporate social performance. Different values will steer IM practitioners in different policy directions. If IM is to be more than a "social gadget," designed to promote the firm's narrow economic objectives, it must be selfconsciously grounded in ethics. Stakeholder analysis and the comprehensive corporate ethic are concepts that can help forge links between ethics and the administrative process, between values and decision-making in IM.

Keywords - Ethics, Decision-Making, Issues, Management, Policy, Values.
\end{abstract}

\section{Introduction}

A definition of ethics is, at a simplistic level, to 'do no harm'. An understanding of the definition of business ethics and ethics in decision making is important in today's business environment. Once you've gained that understanding, it is necessary to consider the impact of ethical decision making and problem solving on your business.

Our actions affect not only ourselves, but also those around us. Many of our professional decisions involve ethics. If we tell a lie, we can lose someone's trust and undermine our own integrity. If we use shoddy materials or workmanship on the job, we can jeopardize the safety of others.

Questions of morality and ethics can be found at all levels of society. Ethical behavior is equally important in the workplace as it is in our personal lives. Everywhere business is conducted, ethics matters.

Ethical decision making requires more than a belief in the importance of ethics. It also requires ethical sensitivity to implications of choices, the ability to evaluate complex, ambiguous and incomplete facts, and the skill to implement ethical decisions effectively.

Issues management is the executive function of strategic public relations that deals with problem solving, organizational policy, long-range planning, and management strategy as well as communication of that strategy internally and externally (Chase, 1977; Ewing, 1981; Hainsworth \& Meng, 1988; Heath, 1997). Issues management frequently handles ethical dilemmas through the identification of issues, research, analysis, and the making of organization-wide policy decisions regarding those issues

Public relations practitioners face many ethical challenges, specifically in issues management (e.g., Bowen \& Heath, 2005; J. Grunig \& L. Grunig, 1996). By its definition, issues management is concerned with defining issues and problems, manages them through internal and external communication with publics, and often confronts conflicting value systems among publics. Therefore, issues management is on the forefront of ethical decision making in an organization (Heath, 1997).

As the ethical conscience of the organization, public relations practitioners should be well versed in both moral philosophy and ethics. This research contributes to moral knowledge and allows practitioners an understanding of that philosophy and the analytical techniques applied by a deontological approach to ethical decision making.

All ethical questions are focused on making a decision.

So how does one go about framing that choice? Initially, of course, a person (or the organization) has to recognize that an ethical issue exists. The issue could be a legal one, or more of a judgment call, but in both cases the question of 'what is in the greatest good' for all stakeholders must be asked (and answered).

In determining right versus wrong, we have to remember that those terms are subjective. That's where understanding the definition of ethics, and relying on a corporate code of ethics, can be very helpful. The code is the baseline by which a person, group, or organization can measure the facts of a case (including whether a determination can be made impartially). It is also important to develop an organization's value statement to reflect your ethical values as well; this will help employees understand your commitment and direction. 
The importance of ethics to business is because the values that you use to build and manage your company need to be rooted in ethical decisions and strategies.

Recently, there has been a lot of media attention given to ethics in decision making; particularly in the workplace. Consumers and society as a whole want to see more corporate accountability. Additionally, we want business to more actively think about not only how a company treats employees, but also how a company's code of ethics extends to all of its stakeholders, such as customers, suppliers, and community.

When analysis and evaluation begins, the rights of the individual and group, the equality of treatment, and the steps taken to remedy the issue or situation in a way that best serves the organization's vision or identity must all come into play. By examining each of these elements, a decision that's cohesive, consistent and appropriate will begin to form. Finally, that decision must be implemented (otherwise you're spinning your wheels).

\section{The Importance of Values and Culture in Ethical Decision Making}

Ethical thinking involves the intricate process used to consider the impact of our actions on the individuals or institution we serve. While most decisions are routine, we can unexpectedly face an ethical dilemma when unusual situations occur suddenly for which an immediate response is needed.

The foundation of ethical decision-making involves choice and balance; it is a guide to discard bad choices in favor of good ones. Therefore, in making ethical decisions, one of the first questions to consider is 'what a reasonable man would do in this situation?'For tougher decisions, advisors may find three rules of management helpful (Hojnacki, 2004).

1. The Rule of Private Gain. If you are the only one personally gaining from the situation, is it is at the expense of another? If so, you may benefit from questioning your ethics in advance of the decision.

2. If Everyone Does It. Who would be hurt? What would the world be like? These questions can help identify unethical behavior.

3. Benefits vs. Burden. If benefits do result, do they outweigh the burden?

When people work closely together on a project, individuals tend to take on the core values of the group. Individuals within a group often compromise their own values in favor of those held by the group. Because of this, groups should use the three rules of management to assess whether their organizational decisions are ethical. Since group dynamics are an increasingly vital measure of organizational success, and standards of behavior are viewed within the context of profit and integrity, it is imperative that the group conceptualize the impact of their decisions.

To be truly comprehensive, advisor development programs must address ethics and the role culture and values play in ethical decision-making. Our institutions have become more diverse. This is true in regard to easily recognizable differences, such as race and age, but also in terms of hidden differences, such as culture and disability. Care must be given to the reexamination of values and perspective, and how these influence so many ethical dilemmas.

\section{The Impact of Ethics on Decision Making}

The decision-making process will always present ethical challenges to managers. Is this the right thing to do? This question is the essence of the ethical dilemma for any decision maker in today's corporations. A collection of factors will be taken in consideration in answering to this question. Is it right for the company? Is it right for the shareholders? Is it right for the society? For the customers? For the decision maker himself? There are many ways to approach the ethical subject, and different ethical values may and will emerge from these different approaches. The way a decision will be evaluated is fully dependent on the values and interests of the person or group of people evaluating that decision. Some of the stakeholders will not care that much if the decision was made based on ethical values counting it generated the results they expected. This is where the risk lies, because the decision maker will also have this in mind when deciding about the subject; depending on how much he or she is results-driven, he or she may overlook some ethical issues in the name of a good outcome and good earnings. This is especially true when the decision maker is a materialist moral philosophy. Shannon Bowen (2002, pg 271) tells us that "moral philosophy can be summed up in three approaches: materialism, utilitarianism, and deontology".

The ground rules about which a decision maker will care are highly dependent on the moral approach. The decision maker may use a self-interest and materialist approach and make decisions that will be always directed towards his or her own benefit; these decisions may sometimes cause also good results for the company even though the decision maker has only the self-benefit in mind. Even though this is not properly a school of moral philosophy (Bowen, 2002, pg 272), it is not rare that managers will make decisions using this approach. A different approach may be used and the decision happens based on the actual number of people benefited by it. Usually this utilitarian approach takes into consideration the consequences of a decision as the 
main method for evaluating its morality. And also, the decision maker may evaluate that the consequences are not really a factor that will determine whether a decision is ethical or not; in this situation deontological approach would be in use.

\section{Addressing Ethics in Decision Making}

It is our intent to focus on the practical application of ethics in decision making. We need to start by creating some clarifying distinctions to facilitate our purpose. First, we must acknowledge the vast amount of research and study on the topic, and recognize that our application of ethics within business decision making, only addresses a small portion of the much broader topic. Second, our goal is to address decision making ethics in view of our decision making model in a way that will enable a consistent application of ethics in the decision making process.

\subsection{Distinguishing Morals from Ethics in Decision Making}

Ethics: Ethics refers to a set of rules that describes acceptable conduct in society. Ethics serve as a guide to moral daily living and helps us judge whether our behavior can be justified.

Morals: Morals are a set of rules or mode of conduct on which society is based. Certain moral elements are universal, such as the laws forbidding homicide and the basic duties of doing good and furthering the well-being of others.

In our research we have found an overwhelming amount of information just to address the meaning or distinction between "morals" and "ethics." There are a large range of views that include the words being synonyms and the word ethics being "moral philosophy," or the study of moral principles. Both relate to determination of right conduct.

For our purpose we will reserve the term "moral" for use in a personal decision making context. This means that we will use "moral" when dealing with personal or life decisions with a focus on "right conduct" as the result of a personal choice. Ethical decision making will be reserved for use in a group decision making context. Specifically, we will address ethical decision making in business as providing the guiding requirements or goals for right conduct. These requirements often come as the result of organizational definition, agreement, or long-standing custom. There is clear recognition that ultimately a personal choice must be made with respect to right conduct, but business ethics will provide the assessment framework for correct behavior in the business organization.

\subsection{Ethics in decision making impacts the choices for words and actions}

In confining ethical decision making to a business or group context, decisions on ethics are necessarily limited to actions and words (e.g., no deceit in sales promotion, use words to manipulate performance, ...). Right behavior can be evaluated though actions and words, but there is no way to know one's thoughts. Per our distinction, thoughts and beliefs (e.g., I want to help and benefit my customer as opposed to I want their money without regards to what is right, personal gain at the cost of someone else's reputation, ...) will be confined to moral decisions that are part of personal decision making.

Clearly our thoughts affect our words and deeds, and in a group context, ethics in decision making can be evaluated through the tangible evidence and outcomes from words and actions. Again, thoughts and motivation are left to the personal realm. As a consequence, evaluation of appropriate ethical behavior will have limitations. In all outcomes there are the following possibilities:

- Right motivation with right action

- Right motivation with wrong action

- Wrong motivation with right action

- Wrong motivation with wrong action

Given the difficulty in exposing true motivation, ethical assessments will inherently be limited to an evaluation emphasis on action or outcome.

\section{Ethical Conflicts}

We are fond of the term ethical or moral dilemmas to refer to intrapersonal conflicts involving our interests, values and various ethical codes.

Values: Values are defined as the acts, customs, and institutions that a group of people regard in a favorable way. Statements of value typically contain words of approval, disapproval, and obligation. Some of these words might be good, bad, should, and should not. However, value judgments do not have to contain specific value words. "That is a lie" does not contain a particular word of disapproval, but the implication that a lie is wrong is understood. 
Here is a partial list of some of the sources of ethical conflicts. These conflicts are sometimes discussed on the concept of moral-expediant conflict or want versus should conflict (Bazerman, Tenbrunsel \& WadeBenzoni, 1998).

1. Personal values and social values

2. Self interests and benefit to others

3. Personal values and organizational rules

4. Ethical codes and benefit to others

5. Honesty and benefit to others

6. Personal values and social norms

\subsection{How to Handle Ethical Issues}

Character and Conscience underlie Ethical Decision Making

Character: Ethics is not just how we think and act. It is also about character. Character drives what we do when no one is looking. Each person has the ability to build, change, or even destroy his or her own character. We can build our character through the way we live-by thinking good thoughts and performing good acts. Similarly, bad thoughts and behavior can destroy our character.

Ethical dilemmas in the workplace can be more effectively dealt with if managers follow a few simple steps:

1. Identify the ethical issues. Ethical issues exist, in a broad sense, whenever one's actions affect others. In the workplace, a manager's decisions might affect employees, customers, suppliers, creditors and shareholders. These are the stakeholders of an organization.

2. Identify alternative courses of action. Every dilemma affords more than just one opportunity. The cautious handling of workplace ethics issues can resolve personal and business dilemmas. By identifying the alternatives, the next step can take place.

3. Using ethical reasoning to decide on a course of action. Ethical reasoning skills are essential to making ethical decisions.

A variety of methods exist including:

Egoism: Egoism looks at each decision by considering the effects of a decision only as it relates to the individual decision-maker. Most ethicists dismiss this method because it fails to consider the consequences on the stakeholders. For example, if a CEO or CFO is dealing with financial statement reporting and wants the statements to look as good as possible regardless of the rules and effects on others, then egoism rules the day.

Enlightened Egoism: This method considers the consequences of alternatives on the stakeholders but ultimately a decision is made based on what's in the best interest of the decision maker. So, a manager would consider the effects on the stakeholders and may decide that since a particular decision is harmful to the stakeholders because manipulatation of the financial statements compromises the validity of those statements, it is in the best interests of the manager to conform the statements to accounting rules.

Utilitarianism: Here the decision-maker evaluates harms and benefits of alternative decisions using a calculus/weighting approach. Under act utilitarianism, the decision would be to select the act where the benefits to the stakeholders exceed the harms (i.e., net benefits are greater than any other act I might take). The problem here is a decision-maker might weigh the alternative to manipulate the statements as having greater value than conforming to the rules. An alternative is to apply rule-utilitarianism where regardless of utilitarian benefits certain rules should never be violated, such as always follow proper accounting rules regardless of the consequences on others.

Rights and Obligations: In this method the decision-maker uses ethical judgment to evaluate the rights of others (i.e., the investors and creditors). These stakeholders have a right to expect accurate and reliable financial statements. Correspondingly, I, as a decision-maker, have an obligation to respect those rights when I select an alternative course of action. Rights Theory follows a universality approach in that I would ask, before deciding, whether I would want others in my position to make the same decision for the same reason if they were faced with a similar dilemma. If so, my action has universal appeal and should be taken.

\section{Conclusion}

This study yielded the following findings. Participants argued that decision making should be consensus-oriented and based on equal participation and continuous discussion. Unfortunately, the lack of consistent, dedicated, and enthusiastic input by member groups was a significant impediment to a more inclusive decision making process for the management of issues. Participants' valued equality - their emphases on being against stereotypes, inequality, and biases was consistent with the deontological paradigm. Moral autonomy was a dominant theme that also emerged through discussion of the sovereign right of each country to decide its own macro-economic/fiscal policies. Transparency was another ethical consideration that the coalition 
used in its issues management. Overall, there was a remarkably high degree of congruence between the philosophical approach of deontology and the beliefs espoused by coalition members.

For making ethical decisions, In short, the Six Pillars can dramatically improve the ethical quality of our decisions, and thus our character and lives.

The Six Pillars of Character: Trustworthiness, Respect, Responsibility, Fairness,. Caring, Citizenship. The Six Pillars of Character are ethical values to guide our choices. The standards of conduct that arise out of those values constitute the ground rules of ethics, and therefore of ethical decision-making.

There is nothing sacrosanct about the number six. We might reasonably have eight or 10, or more. But most universal virtues fold easily into these six. The number is not unwieldy and the Six Pillars of Character can provide a common lexicon.

\subsection{Trustworthiness}

When others trust us, they give us greater leeway because they feel we don't need monitoring to assure that we'll meet our obligations. They believe in us and hold us in higher esteem. That's satisfying. At the same time, we must constantly live up to the expectations of others and refrain from even small lies or self-serving behavior that can quickly destroy our relationships.

Simply refraining from deception is not enough. Trustworthiness is the most complicated of the six core ethical values and concerns a variety of qualities like honesty, integrity, reliability and loyalty.

\subsection{Respect}

People are not things, and everyone has a right to be treated with dignity. We certainly have no ethical duty to hold all people in high esteem, but we should treat everyone with respect, regardless of who they are and what they have done. We have a responsibility to be the best we can be in all situations, even when dealing with unpleasant people.

\subsection{Responsibility}

Life is full of choices. Being responsible means being in charge of our choices and, thus, our lives. It means being accountable for what we do and who we are. It also means recognizing that our actions matter and we are morally on the hook for the consequences. Our capacity to reason and our freedom to choose make us morally autonomous and, therefore, answerable for whether we honor or degrade the ethical principles that give life meaning and purpose.

\subsection{Fairness}

What is fairness? Most would agree it involves issues of equality, impartiality, proportionality, openness and due process. Most would agree that it is unfair to handle similar matters inconsistently. Most would agree that it is unfair to impose punishment that is not commensurate with the offense. The basic concept seems simple, even intuitive, yet applying it in daily life can be surprisingly difficult. Fairness is another tricky concept, probably more subject to legitimate debate and interpretation than any other ethical value. Disagreeing parties tend to maintain that there is only one fair position (their own, naturally). But essentially fairness implies adherence to a balanced standard of justice without relevance to one's own feelings or inclinations.

\subsection{Caring}

If you existed alone in the universe, there would be no need for ethics and your heart could be a cold, hard stone. Caring is the heart of ethics, and ethical decision-making. It is scarcely possible to be truly ethical and yet unconcerned with the welfare of others. That is because ethics is ultimately about good relations with other people.

\subsection{Citizenship}

Citizenship includes civic virtues and duties that prescribe how we ought to behave as part of a community. The good citizen knows the laws and obeys them, yes, but that's not all. She volunteers and stays informed on the issues of the day, the better to execute her duties and privileges as a member of a self-governing democratic society. She does more than her "fair" share to make society work, now and for future generations. Such a commitment to the public sphere can have many expressions, such as conserving resources, recycling, using public transportation and cleaning up litter. The good citizen gives more than she takes. 


\section{References}

[1]. Buck, J., Moore J., Schwartz, M., and Supon S. (2001). What is Ethical Behavior for an Academic Adviser? The Mentor: An Academic Advising Journal, 3(1) . Retrieved April 23, 2004.

[2]. Hojnacki, William. (2004). Three Rules of Management. In Managerial Decision Making, graduate course conducted in the School of Public and Environmental Affairs, Indiana University South Bend.

[3]. Chmielewski, C., (2004). The Importance of Values and Culture in Ethical Decision.

[4]. Bowen, Shannon A. (2002). Elite Executives in Issues Management: The Role of Ethical Paradigms in Decision Making. Journal of Public Affairs. February 2002, Vol. 2 Number 4 pg 270-283. Retrieved from EBSCO Host on February 23, 2004.

[5]. Banaji, Mahzarin R., Bazerman, Max H., Chugh, Dolly (2003). How (Un)Ethical Are You?Harvard Business Review. December 2003, Vol 81, Issue 12, p56, 9p, 13c. Retrieved from EBSCO Host on February 23, 2004. AN 11587432.

[6]. Bastien, J. Robert (1997). Can Ethics Improve The Bottom Line? Security Management. August, 1997. Vol. 41, Iss. 8, Pg. 136, 2 pgs. Retrieved from Proquest on February 23, 2004. Doc ID 13358297.

[7]. Stanley, T. L. (2002). The Making of an Ethical Manager. The American Salesman. July 2002, Vol. 47, Iss. 7; pg. 3, 7 pgs. Retrieved from Proquest on February 23, 2004. Doc ID 127278251.

[8]. Bazerman, M. H., Tenbrunsel, A. E., \& Wade-Benzoni, K. A. 1998. Negotiating with yourself and losing: Making decisions with internal competing preferences. Academy of Management Review, 23(2): 225-241. 